\title{
The Importance of Both Charge Exchange and Proton Transfer in the Analysis of Polycyclic Aromatic Compounds Using Atmospheric Pressure Chemical Ionization Mass Spectrometry
}

\author{
Beata M. Kolakowski, ${ }^{*}$ J. Stuart Grossert, and Louis Ramaley \\ Department of Chemistry, Dalhousie University, Halifax, Nova Scotia, Canada
}

\begin{abstract}
The response of atmospheric pressure chemical ionization (APCI) mass spectrometry to selected polycyclic aromatic compounds (PACs) was examined in a Micromass Quattro atmospheric pressure ion source as a function of both solvents and source gases. Typical PACs found in petroleum samples were represented by mixtures of naphthalene, fluorene, phenanthrene, pyrene, fluoranthene, chrysene, triphenylene, perylene, carbazole, dibenzothiophene, and 9-phenanthrol. A large range of different gases in the APCI source was studied, with emphasis on nitrogen, air, and carbon dioxide. Solvents used included water-acetonitrile, acetonitrile, dichloromethane, and hexanes. The signal responses were dependent on both the gases and solvents used, as was the ionization mechanism, as indicated by the degree of protonation with respect to the level of charge exchange. The combination of carbon dioxide in the nebulizer gas stream with nitrogen in the other streams gave a three- to fourfold better sensitivity than using nitrogen alone for both test mixtures and for complex samples. (J Am Soc Mass Spectrom 2004, 15, 301-310) @ 2004 American Society for Mass Spectrometry
\end{abstract}

$\mathrm{P}$ olycyclic aromatic compounds (PACs) are found in a wide variety of sources, both in endogenous samples and in those arising from human activities. The PACs occurring in crude oil samples are known to compromise the activity of catalysts in oil refining operations. They affect both combustion processes in gasoline and diesel motors, as well as the nature of combustion byproducts. In addition, there are firm indications that many PACs have effects on the health of living organisms. Hence, the determination of PACs has been of great interest for many years, but complete, detailed analyses have been hampered by complex matrices, trace level concentrations, a large number of isomers, many similar compounds and a lack of reference standards. Special methods of analysis beyond classical procedures include multidimensional chromatographic separations with mass spectrometric detection, high resolution mass spectrometry and atmospheric pressure mass spectrometric methods [1-4]. Atmospheric pressure chemical ionization mass spectrometry (APCI-MS) is an important technique when

Published online January 15, 2004

Address reprint requests to Dr. J. S. Grossert, Department of Chemistry, Dalhousie University, Halifax, Nova Scotia B3H 4J3, Canada. E-mail: j.s.grossert@dal.ca

${ }^{*}$ Current address: Ionalytics Corp., M-50 IPF, 1200 Montreal Road, ON K1A 0R6, Canada. interfacing mass spectrometry to high-performance liquid chromatography (HPLC) for the analysis of PACcontaining samples. The major drawback of APCI-MS in this regard for the nonpolar polycyclic aromatic hydrocarbon (PAH) portion of a PAC fraction is that the sensitivity of this ionization technique is often poor under conditions which are needed to accomplish satisfactory chromatographic separations [5].

In the preceding paper [6] we presented results from a study in which we examined the production of positive ions in a Micromass Quattro APCI ion source with a "pepper pot" counter electrode, using different source gases and solvents. These studies have led to some understanding of the conditions present in this type of source. As a result of the rich chemistry occurring in the source, both radical cations and protonated molecules were observed, with equilibrium conditions prevailing; the ions which were detected are those which are thermodynamically most stable. The case of PAHs is especially interesting since molecular ions can be expected to be produced by both direct ionization and charge exchange, whereas protonated molecules are produced by proton transfers, but for these to be effective, strong Brønsted acids must be present [7].

In the present paper we describe how the use of different source gases in combination with various solvents can influence the detection of PACs. These 
effects were most readily studied by using a mix of PACs designed to simulate those found in a typical lighter fraction refined from a crude oil mixture. The studies were undertaken to understand better the processes involved in APCI and to seek improvements in the analysis of PAC-containing samples.

\section{Experimental}

\section{Materials and Solutions}

Naphthalene (Fisher, Nepean, Ontario, Canada), phenanthrene (Anachemia, Montreal, Canada), fluorene, chrysene, pyrene, fluoranthene, triphenylene, perylene, carbazole, dibenzothiophene and 9-phenanthrol (Aldrich, Oakville, Ontario, Canada) were used as received. A light gas oil sample was supplied by Syncrude Canada Ltd. Solvents (Edmonton, Canada) (water-acetonitrile [50:50 vol/vol], acetonitrile [MeCN], dichloromethane [DCM], and hexanes) and the compressed gases nitrogen, air, carbon dioxide, carbon monoxide, oxygen, methane, and hydrogen are described in the preceding paper [6]. Nitrogen obtained from a pressurized cylinder and nitrogen obtained by evaporation from a pressurized Dewar flask are referred to as T-nitrogen (or $\mathrm{TN}_{2}$ ) and D-nitrogen (or $\mathrm{DN}_{2}$ ), respectively. Air from both the building supply and from commercially supplied cylinders was studied, but, as described earlier [6], the air in the building supply was contaminated to such an extent that it did not provide satisfactory results. Thus all results reported below pertain to air obtained in commercial high-pressure cylinders.

\section{Standard Mixtures of PACs}

Structures of the PACs used in this study are shown in Scheme 1 with other details being given in Table 1. The PACs were divided into two groups to avoid overlaps in the $m / z$ values. Group 1 consisted of naphthalene (1, Naph), fluorene (2, Fluo), phenanthrene (3, Phen), pyrene (4, Pyr), chrysene (6, Chry), dibenzothiophene (10, DBT), and 9-phenanthrol (11, 9-Phtr), and Group 2 consisted of 1, 3, fluoranthene (5, Flrn), triphenylene (7, Tri), perylene (8, Pery), and carbazole (9, Carb). Both groups contained $\mathbf{1}$ and $\mathbf{3}$ to provide a check on reproducibility of the experiments. Stock solutions were made up in acetonitrile, dichloromethane and hexanes except that $\mathbf{8}$ was too insoluble in hexanes for it to be included in this solvent. Each stock solution was diluted one hundredfold with the same solvent to yield analytical solutions with a concentration for each PAC of $10 \mu \mathrm{M}$. The analytical solution with $50: 50$ ( $\mathrm{vol} / \mathrm{vol}$ ) acetonitrile-water was made up by diluting the stock solution in acetonitrile with 50:50 ( vol/vol) acetonitrilewater.
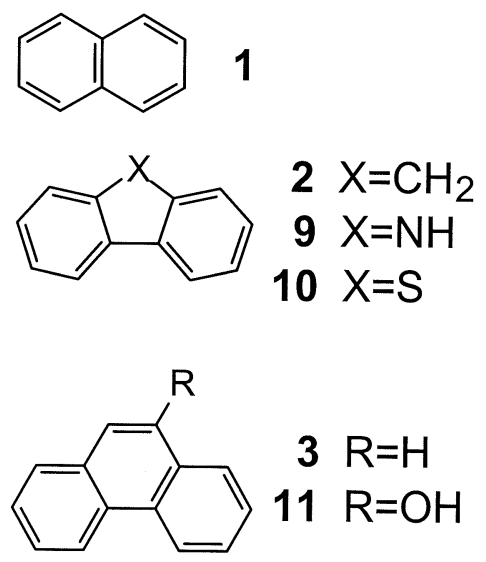

$3 \mathrm{R}=\mathrm{H}$ $11 \mathrm{R}=\mathrm{OH}$<smiles></smiles><smiles></smiles><smiles>c1ccc2c(c1)c1ccccc1c1ccccc21</smiles>

4<smiles>c1cc2cccc3c4cccc5cccc3c(c1)c-5c4-2</smiles>

Scheme 1

\section{Instrumentation and Procedures}

The mass spectrometric instrumentation, gas distribution system and liquid handling equipment were detailed in the preceding paper [6]. Regular mass spectrometric operating parameters (unless otherwise noted) were: corona voltage $=4.0 \mathrm{kV}(4.5 \mathrm{kV}$ for DCM), optimized cone voltage $=30 \mathrm{~V}$, source temperature $=$ $120^{\circ} \mathrm{C}\left(100^{\circ} \mathrm{C}\right.$ for hexanes), probe temperature $=$ $350^{\circ} \mathrm{C}$; bath and sheath gas flow rates $=300$ standard liters per h (sLph); nebulizer gas flow rate $=30 \mathrm{sLph}$.

When switching between different gases, the solvent flow was stopped, undesired gas bled out of the appropriate lines, new gas introduced, the solvent flow re-initiated and a ten minute stabilization period observed. A solvent flow of $0.200 \mu \mathrm{L} \mathrm{min}{ }^{-1}$ was maintained with sample injections of $200 \mu \mathrm{L}$ being made using a Rheodyne (Supelco, Ontario, Canada) injector valve. All analyses with a given solvent system, including all gas combinations, were performed before changing between solvents. Care was taken to rinse the injection loop three times with each new solvent before making analyses.

Single ion monitoring (SIM) was used for the analyses reported here. Dwell times of $0.25 \mathrm{~s}$ for flowinjection analyses and $0.20 \mathrm{~s}$ for HPLC analyses at the $\mathrm{m} / \mathrm{z}$ values of both the molecular ion and the protonated molecule for each component of the mixture under test were employed. For both PAC Analysis Groups (Table 1) ten scans of background were acquired, the sample was injected, and data acquisition was continued until 5 
Table 1. Properties of polycyclic aromatic compounds used in this work

\begin{tabular}{|c|c|c|c|c|}
\hline Compound & $\begin{array}{l}\text { Ionization energy } \\
(\mathrm{eV})^{\mathrm{a}, \mathrm{c}}\end{array}$ & $\begin{array}{l}\text { Proton affinity } \\
\left(\mathrm{kJ} \mathrm{mol} \mathrm{mol}^{-1}\right)^{\mathrm{b}, \mathrm{c}}\end{array}$ & $\mathrm{M}^{+}, m / z$ & Group \\
\hline Naphthalene, 1 & 8.1 & 803 & $\mathrm{C}_{10} \mathrm{H}_{8}, 128$ & 1,2 \\
\hline Fluorene, 2 & 7.9 & 832 & $\mathrm{C}_{13} \mathrm{H}_{10}, 166$ & 1 \\
\hline Phenanthrene, 3 & 7.9 & 823 & $\mathrm{C}_{14} \mathrm{H}_{10}, 178$ & 1,2 \\
\hline Pyrene, 4 & 7.4 & 869 & $\mathrm{C}_{16} \mathrm{H}_{10}, 202$ & 1 \\
\hline Fluoranthene, 5 & 7.9 & 829 & $\mathrm{C}_{16} \mathrm{H}_{10}, 202$ & 2 \\
\hline Chrysene, 6 & 7.6 & 841 & $\mathrm{C}_{18} \mathrm{H}_{12}, 228$ & 1 \\
\hline Triphenylene, 7 & 7.9 & 819 & $\mathrm{C}_{18} \mathrm{H}_{12}, 228$ & 2 \\
\hline Perylene, 8 & 7.0 & 860 & $\mathrm{C}_{20} \mathrm{H}_{12}, 252$ & 2 \\
\hline Carbazole, 9 & 7.6 & $\sim 940^{d}$ & $\mathrm{C}_{12} \mathrm{H}_{9} \mathrm{~N}, 167$ & 2 \\
\hline Dibenzothiophene, 10 & $\sim 8.1^{\mathrm{d}}$ & $\sim 890^{d}$ & $\mathrm{C}_{12} \mathrm{H}_{8} \mathrm{~S}, 184$ & 1 \\
\hline 9-Phenanthrol, 11 & $\sim 7.6^{\mathrm{d}}$ & $\sim 880^{d}$ & $\mathrm{C}_{14} \mathrm{H}_{10} \mathrm{O}, 194$ & 1 \\
\hline
\end{tabular}

${ }^{a}$ From Lias, S. G.; Bartmess, J. E.; Liebman, J. F.; Holmes, J. L.; Levin, R. D.; Mallard, W. G. J. Phys. Chem Reference Data 1988,17, Suppl. 1, 40-646. bFrom Hunter, E. P.; Lias, S. G. J. Phys. Chem. Reference Data 1998, 27, 413.

'Some data also from Lias, S. G.; Bartmess, J. E.; Liebman, J. F.; Holmes, J. L.; Levin, R. D.; Mallard, W. G. lon Energetics Data in NIST Chemistry WebBook, NIST Standard Reference Database Number 69; Eds. Linstrom, P. J.; Mallard, W. G. July 2001, National Institute of Standards and Technology, Gaithersburg MD, 20899 (http://webbook.nist.gov).

${ }^{\mathrm{d}}$ Ionization data estimated conservatively from those of similar compounds, for example, indole has IE $=7.15 \mathrm{eV}$ and $\mathrm{PA}=933 \mathrm{~kJ}$ mol ${ }^{-1}$.

scans after the total ion current (TIC) had returned to the baseline. An average background was subtracted from the analytical signal after the injected sample was detected and the responses (in counts) at the $\mathrm{m} / \mathrm{z}$ values for the molecular ions and protonated molecules of each PAC in the reference mixture were recorded. All analyses were done in triplicate.

\section{The Analysis of a Light Gas Oil}

A preparative fractionation of a light gas oil sample into broad compound classes was carried out using a silica column (Supelco LC-Si, Ontario, Canada) $10 \mathrm{~mm} \times 250$ $\mathrm{mm}, 5$ micron particles with hexanes as the eluent. The fraction studied here was taken late in the chromatogram (when pyrenes were eluting), reduced to near dryness using a Kuderna-Danish (Supelco, Oakville, Ontario, Canada) apparatus and made up in acetonitrile [8]. High performance liquid chromatography (HPLC) was carried out on this fraction using a HewlettPackard/Agilent 1100 system (Missisauga, Ontario, Canada) with $\mathrm{MeCN}$ as the mobile phase at a flow rate

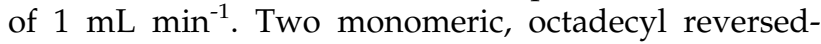
phase Supelco LC-18 columns $(4.6 \mathrm{~mm}$ by $25 \mathrm{~cm}, 5$ micron particles) were coupled together and immersed in an ice bath at $0{ }^{\circ} \mathrm{C}$ [9]. The mass spectrometer was run in the $\mathrm{APCI}(+) \mathrm{SIM}$ mode observing the ions at $\mathrm{m} / \mathrm{z}$ $216,217,220,221,230,231,232,233,242,243,256$, and 257.

\section{Results and Discussion}

In the preceding paper we examined the ions produced by different gases and solvents in the Micromass Quattro APCI source. Although the gas streams contribute a major portion of the molecules present in the APCI source, vaporized solvent molecules also contribute a significant fraction of the molecules. The analytes come into intimate contact with both the vaporized solvent molecules and the nebulizer gas molecules. Their contact with the other gases depends on the time they spend in the source and on the mixing of the separate gas streams. It is known that solvent mixtures such as acetonitrile-water can give a much lower mass spectral response for non-polar compounds, such as PAHs, compared with an aprotic solvent such as acetonitrile [5]. We have explored the effects on signal intensities of using different solvents or solvent mixtures, as well as of changing one or more of the gas streams. The solvents studied included acetonitrile-water, acetonitrile, dichloromethane and hexanes. Single gases used were nitrogen, air, oxygen, carbon dioxide, carbon monoxide, hydrogen, and methane. Of these gases, hydrogen, oxygen, and methane provided lower sensitivities than the other gases; also, hydrogen caused source cooling and deterioration of the corona needle. Therefore, these three gases were not included in the more detailed studies described below. Even though carbon monoxide provided slightly higher sensitivity in a few cases as compared to nitrogen, it also was not studied in detail since the cost and safety considerations would outweigh the small increases in sensitivity sometimes observed.

Nitrogen, air, and carbon dioxide were studied in some detail. The gas-distribution system enabled any combination of gases to be supplied to the nebulizer, sheath and bath gas streams, although air was not used with hexanes for safety reasons. Experiments with two gases were done in two ways, the first being with gas one in the bath and sheath $(B+S)$ gas streams and gas two in the nebulizer (N) stream, the second being with gas one in the bath gas (B) stream and gas two in the nebulizer and sheath $(\mathrm{N}+\mathrm{S})$ gas streams. In these experiments carbon dioxide was always gas two. No two-gas experiments were performed where the sheath gas was different from the bath and nebulizer gases. Experiments with different gases in all three streams were also carried out, but no combination provided 

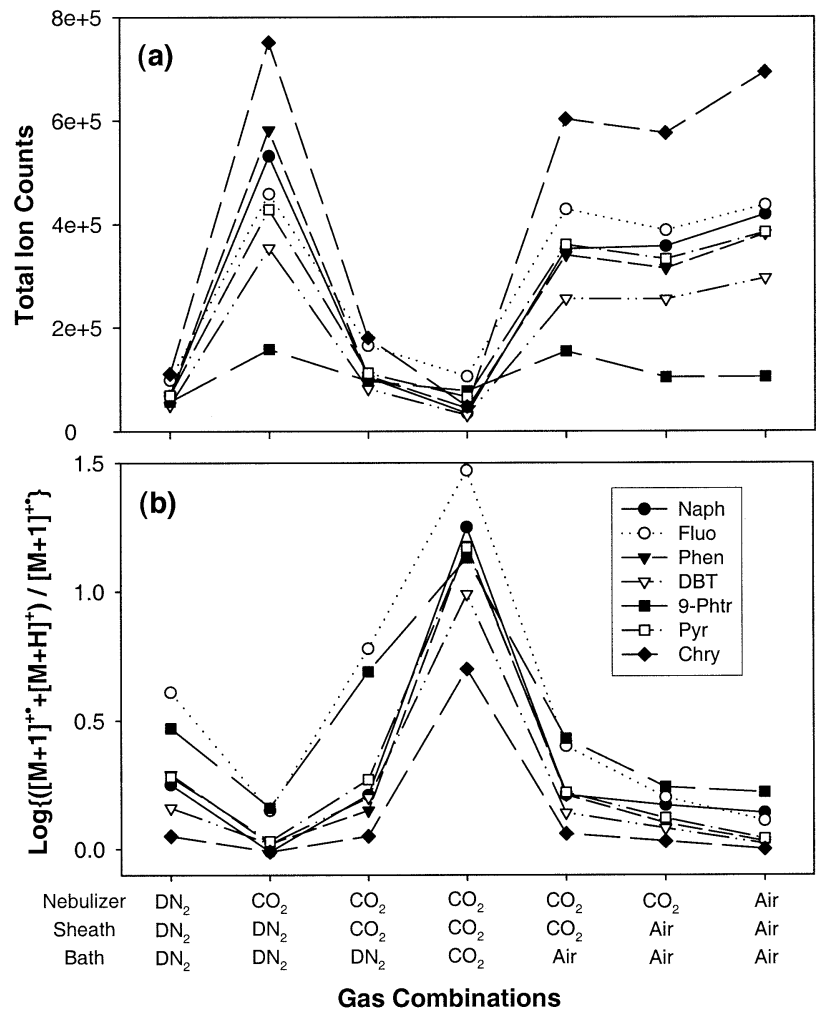

Figure 1. The total signal (a) and protonation ratio (b) for Group 1 compounds for different gas combinations using $\mathrm{MeCN}$ as solvent.

results that were superior to those with only two gases. Thus, these experiments are not reported here.

The study of mixtures by flow injection methods, as opposed to the injection of single compounds or the separation of mixtures by HPLC, shortened considerably the time required for data acquisition, but the question of interferences between analytes must then be considered. Even though APCI is not as sensitive to matrix effects as, for example, electrospray ionization and the concentrations of the analytes studied were low $(10 \mu \mathrm{M})$, compound interactions were studied using solutions of pyrene alone and combined in various mixtures with other PACs in hexanes. No evidence was found to suggest any influence of the other PACs on either the total signal strength or on the ratio of the protonated molecule to the molecular ion of pyrene. It should be noted, however, that not all PACs nor all solvents were tested in this fashion. Although the full-scan results are not reported here, full-scan data as well as SIM data were obtained for a range of the measurements. All results agreed within experimental error and no additional large peaks were observed in the full-scan data; thus, the SIM data can be taken as representative of the mass spectrometric behavior of the compounds studied.

The data for nitrogen, air and carbon dioxide are presented in Figures 1, 2, 3, 4, 5 and 6. The "a" sections of these figures show the total ion counts, that is the
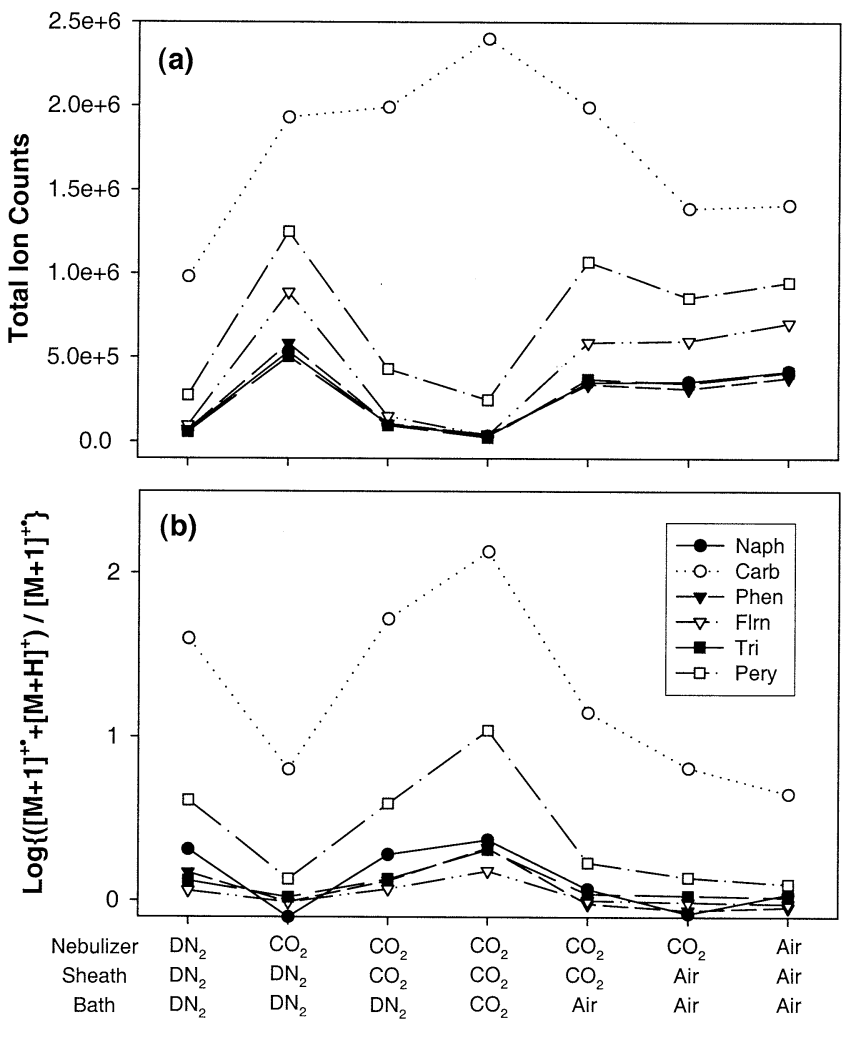

Gas Combinations

Figure 2. The total signal (a) and protonation ratio (b) for Group 2 compounds for different gas combinations using $\mathrm{MeCN}$ as solvent.

sum of the ion counts for the molecular ion peak and the $[\mathrm{M}+1]$ peak (which includes the contributions from both the $[\mathrm{M}+1]^{+\cdot}$ and $[\mathrm{M}+\mathrm{H}]^{+}$ions), for the compounds studied. The " $\mathrm{b}$ " sections show the contribution of protonation to the total ion current. This is presented as the logarithm (for better differentiation of the various curves) of the ratio of the total counts in the $[M+1]$ peak to the counts that should arise from the [M $+1]^{+\cdot}$ ion (as calculated from the counts in the $\mathrm{M}^{+\cdot}$ peak). A value of zero indicates that there is no protonation, a negative value is the result of data imprecision and also indicates no protonation; values greater than about 0.7 indicate that protonation is the major source of ions for a particular compound. The results for D-nitrogen and T-nitrogen were essentially identical and therefore only results for D-nitrogen are presented in the figures.

The data for acetonitrile are presented in Figures 1 and 2. Air in all gas streams provides good sensitivity. The combination of carbon dioxide $(\mathrm{N})$ and nitrogen $(\mathrm{B}$ $+S)$ provided equal or better sensitivity than air and is a more inert combination. Carbon dioxide in all gas streams strongly favors proton transfer but showed poor sensitivity, except for carbazole (9), which is preferentially ionized by proton transfer in all solvents (see below). Thus, the higher sensitivity exhibited by air and by the combination of carbon dioxide $(\mathrm{N})$ plus 

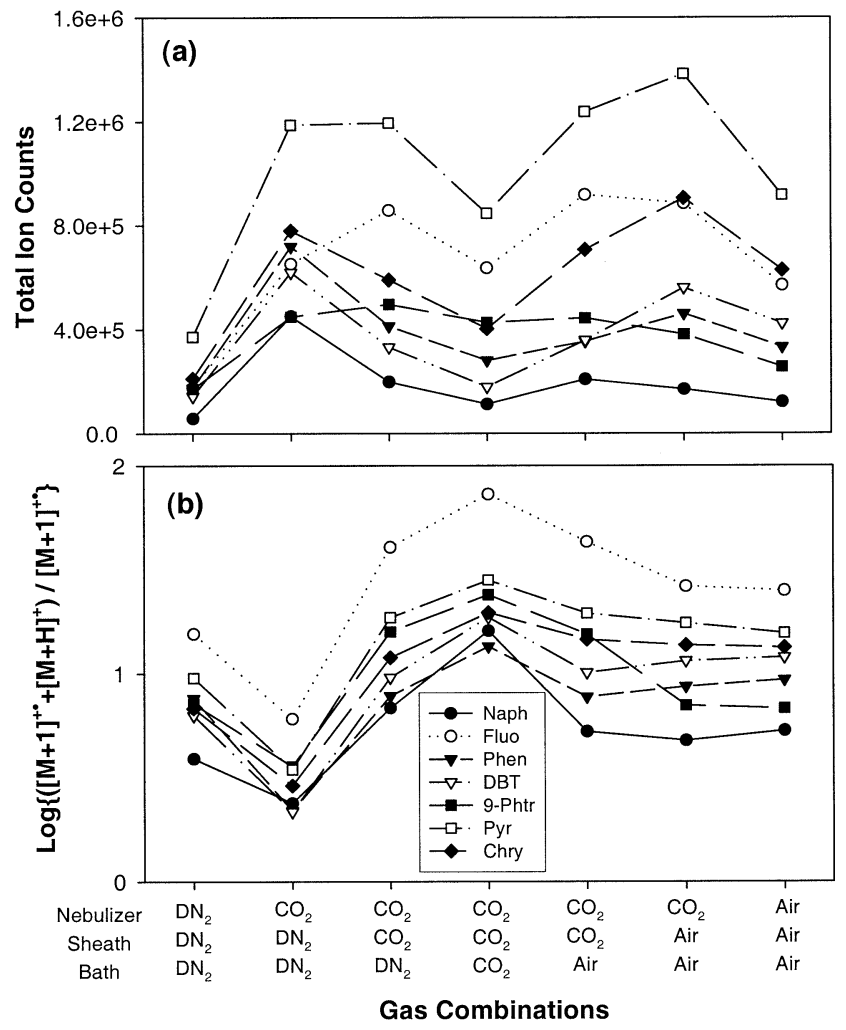

Figure 3. The total signal (a) and protonation ratio (b) for Group 1 compounds for different gas combinations using DCM as solvent.

nitrogen $(B+S)$ is due to a strong increase in ionization by charge exchange processes. The influence of air (oxygen) in increasing the amount of charge exchange might be expected from the results reported in the previous paper regarding the effect of air on the production of radical cations of acetonitrile [6]. Except for the case of carbazole (9) with carbon dioxide in all three gas streams, charge exchange is the preferred ionization mechanism in acetonitrile for the compounds in this study. Results from dibenzothiophene (10) and 9-phenanthrol (11) are comparable to those from the PAHs studied, but the behavior of carbazole (9) is distinctly different.

As observed by others [5], the sensitivity obtained in a 50:50 (vol/vol) acetonitrile-water mixture was much less than that for pure acetonitrile. Charge exchange was reduced by a factor of 10 to 20 in acetonitrile-water. Proton transfer was reduced also, but to a lesser and more varied extent, probably due to the greater presence of various proton-water clusters in this solvent mixture. As in pure acetonitrile, the presence of carbon dioxide in at least one gas stream increased proton transfer; carbon dioxide in all gas streams produced the greatest amount of proton transfer, while the presence of air (oxygen) increased charge exchange. A maximum in sensitivity with carbon dioxide $(\mathrm{N})$ and nitrogen $(\mathrm{B}+$ S) was also observed (due to an increase in charge exchange), but it was much less pronounced than for
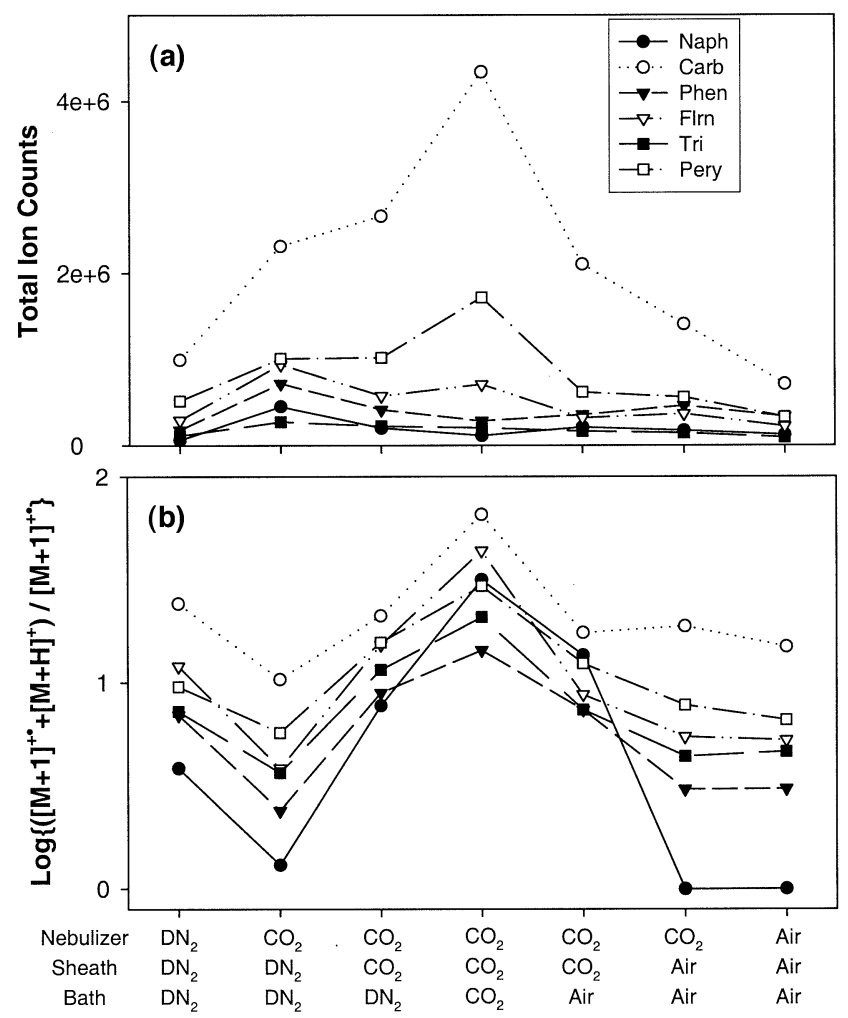

Gas Combinations

Figure 4. The total signal (a) and protonation ratio (b) for Group 2 compounds for different gas combinations using DCM as solvent.

pure acetonitrile. The best sensitivity using the acetonitrile-water mixture for compounds which preferentially undergo charge exchange is obtained with air in all gas streams; for compounds which preferentially undergo proton transfer, the best sensitivity was found with either carbon dioxide in all gas streams, or in the nebulizer and sheath streams with air as bath gas. Since the behavior of the acetonitrile-water mixture is similar to that of pure acetonitrile, but with decreased sensitivity and with the exceptions noted above, these data are not presented in the figures.

The data for dichloromethane are shown in Figures 3 and 4. Some of the same trends are seen with this solvent as with acetonitrile. The presence of carbon dioxide tended to promote proton transfer, with the combination of carbon dioxide $(\mathrm{N})$ and nitrogen $(\mathrm{B}+\mathrm{S})$ providing both higher sensitivity for many compounds and an increase in charge exchange. In general, dichloromethane both gave rise to somewhat higher ion counts and promoted proton transfer to a much larger extent than acetonitrile. With the exception of carbazole (9) and perylene (8), carbon dioxide $(\mathrm{N})$ and either nitrogen or air $(B+S)$ provided the best sensitivities. Although differences in sensitivity and ionization mechanism exist between different gas combinations, these are not as prominent in the case of dichloromethane as they are for acetonitrile. Again, carbazole (9) was 

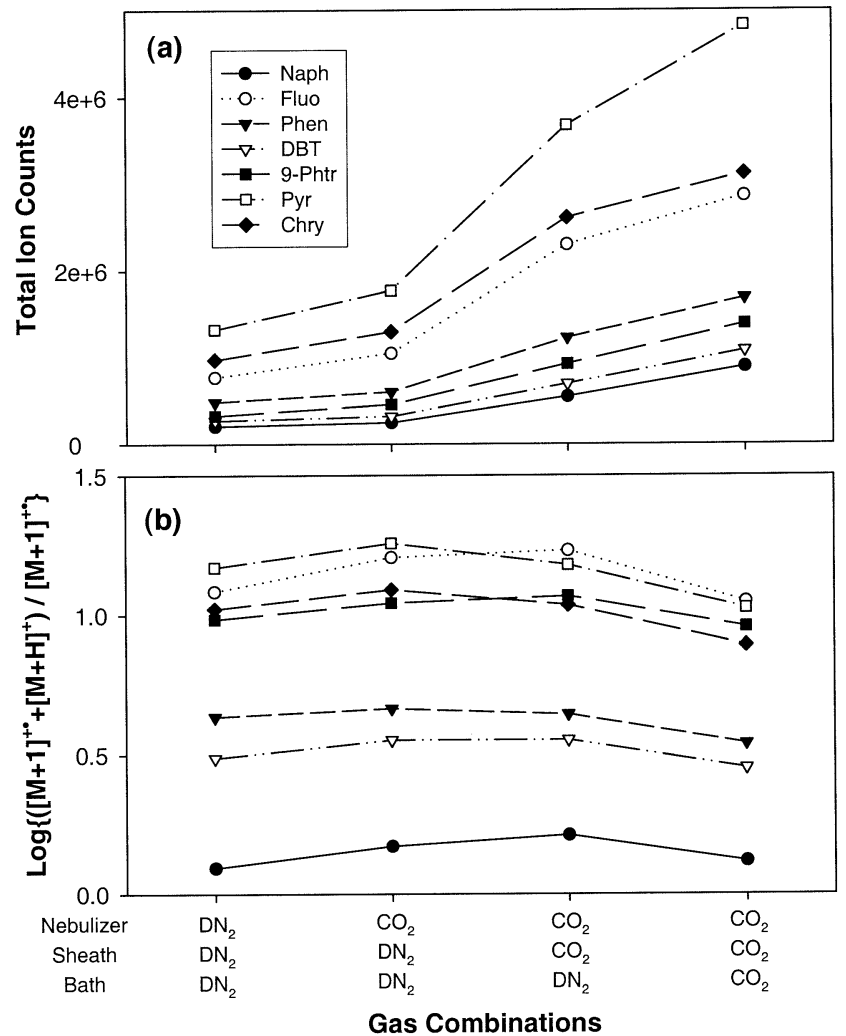

Figure 5. The total signal (a) and protonation ratio (b) for Group 1 compounds for different gas combinations using hexanes as solvent.

most readily detected and showed the highest level of protonation. The other two compounds containing heteroatoms $(\mathbf{1 0}, \mathbf{1 1})$ showed no special features.

The data for hexanes are shown in Figures 5 and 6, with the responses in this solvent being somewhat different than in the other solvents. Various gas combinations do not affect the ionization mechanism to any extent. Proton transfer is the preferred ionization mechanism in all gas combinations for most compounds, naphthalene (1) being a notable exception. Carbon dioxide in all streams provided the highest overall sensitivity for all compounds, but a relatively lower amount of protonation. Neither of these characteristics was found with the other solvents. The increase in sensitivity using hexanes with increasing carbon dioxide content in the gas streams is due to increases in both proton transfer and charge exchange. A high level of charge exchange from PAHs in hexanes is perhaps not unexpected since this process was also observed for benzene and its alkylated derivatives in a regular CI source with hexane or octane as reagent gases [10]. Of all the solvents studied, the overall ion counts were highest in hexanes, especially with carbon dioxide in all gas streams.

Several points emerge from examining these data. Reproducibility for the ion counts from naphthalene (1) and phenanthrene (3), present in both groups 1 and 2, was typically $\pm 10-15 \%$, with only the intensities of two
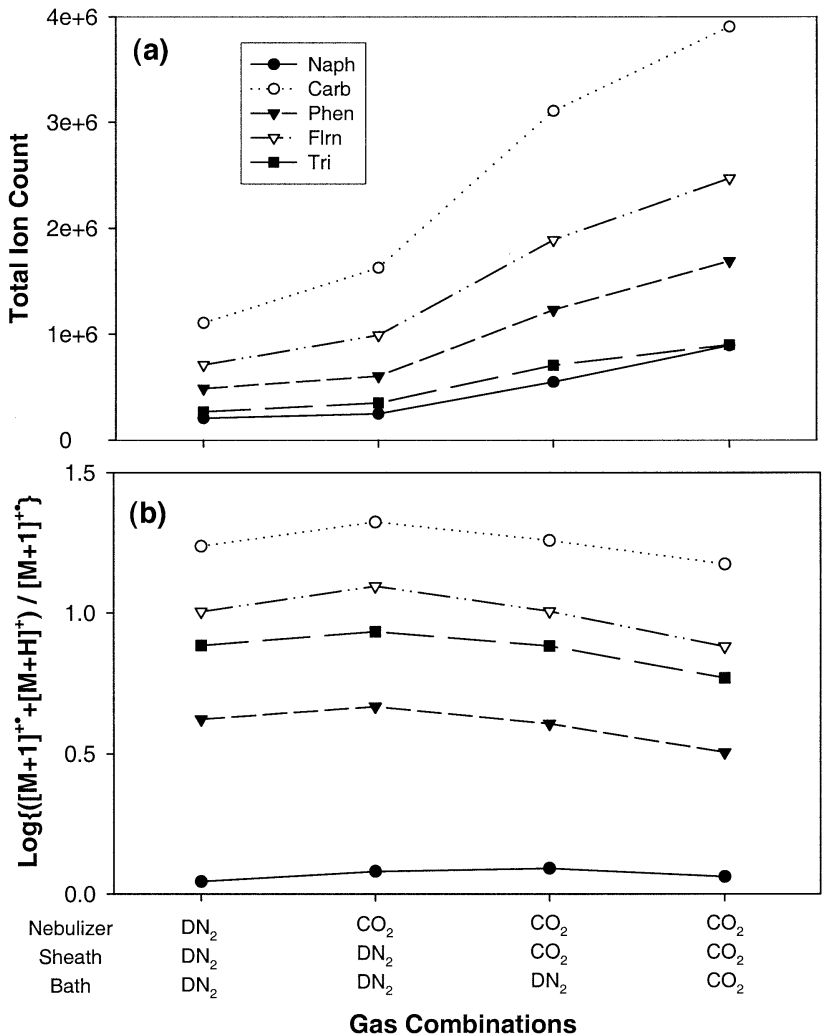

Figure 6. The total signal (a) and protonation ratio (b) for Group 2 compounds for different gas combinations using hexanes as solvent.

pairs of ions, both protonated naphthalenes of relatively low intensities, being $\pm 30 \%$. The absolute signal intensities increase in the order of acetonitrile- $\mathrm{H}_{2} \mathrm{O} \ll$ acetonitrile $<$ dichloromethane $<$ hexanes. When the total ion counts for the seven PAHs, 1-7, using one of three gas stream combinations, nitrogen $(\mathrm{B}+\mathrm{S}+\mathrm{N})$, nitrogen $(\mathrm{B}+\mathrm{S})$ with carbon dioxide $(\mathrm{N})$, or carbon dioxide $(\mathrm{B}+$ $\mathrm{S}+\mathrm{N}$ ), are summed, some significant trends become apparent. These data are collected in Table 2 and show a steady increase in the total ion counts when going from acetonitrile to dichloromethane to hexanes when comparing the same source gas combinations. On dividing these counts into two parts, namely those from the molecular ions $\left(\mathrm{M}^{+*}\right.$, produced by direct ionization

Table 2. Summation of ion counts $\left(\times 10^{-3}\right)$ for PAHs 1-7 in three solvents with three gas stream combinations

\begin{tabular}{lrrr}
\hline Solvent gas & TIC & $\mathrm{M}^{+\cdot}$ & {$\left[\mathrm{M}+\mathrm{H}^{+}\right.$} \\
\hline \hline $\mathrm{MeCN} / \mathrm{DN}_{2}(\mathrm{~B}+\mathrm{S}+\mathrm{N})$ & 573 & 441 & 56 \\
$\mathrm{MeCN} / \mathrm{DN}_{2}(\mathrm{~B}+\mathrm{S})+\mathrm{CO}_{2}$ (N) & 4140 & 3520 & 34 \\
$\mathrm{MeCN} / \mathrm{CO}_{2}(\mathrm{~B}+\mathrm{S}+\mathrm{N})$ & 362 & 144 & 194 \\
$\mathrm{DCM} / \mathrm{DN}_{2}(\mathrm{~B}+\mathrm{S}+\mathrm{N})$ & 1390 & 542 & 754 \\
$\mathrm{DCM} / \mathrm{DN}_{2}(\mathrm{~B}+\mathrm{S})+\mathrm{CO}_{2}(\mathrm{~N})$ & 5000 & 3200 & 1260 \\
$\mathrm{DCM} / \mathrm{CO}_{2}(\mathrm{~B}+\mathrm{S}+\mathrm{N})$ & 3190 & 520 & 2580 \\
Hexanes $/ \mathrm{DN}_{2}(\mathrm{~B}+\mathrm{S}+\mathrm{N})$ & 4740 & 1780 & 2660 \\
Hexanes $/ \mathrm{DN}_{2}(\mathrm{~B}+\mathrm{S})+\mathrm{CO}_{2}(\mathrm{~N})$ & 6330 & 2100 & 3870 \\
Hexanes $/ \mathrm{CO}_{2}(\mathrm{~B}+\mathrm{S}+\mathrm{N})$ & 16800 & 7290 & 8230 \\
\hline
\end{tabular}


or by charge exchange) and those from protonated molecules $\left([\mathrm{M}+\mathrm{H}]^{+}\right.$, produced by proton transfer from stronger Brønsted acids), it was apparent that the signal strengths for BOTH types of ions increased significantly for the same solvent sequence when comparing the source gas combinations nitrogen $(B+S+N)$ and carbon dioxide $(B+S+N)$. The source gas combination of nitrogen $(B+S)$ and carbon dioxide $(N)$ showed a reversal of this trend for molecular ions, but a significant increase for protonated molecules in this solvent series.

The data in Table 2 show clearly that the more conventional method of using acetonitrile as eluent in reversed-phase HPLC separations of PAH mixtures coupled with APCI-MS detection using only nitrogen for the source gases is rather insensitive and that the response can be significantly improved by changing the gas streams of the APCI source.

There are some aspects of the data for which explanations are not readily obvious. The first of these is that the use of a significant amount of carbon dioxide in the gas streams apparently favors significantly more proton transfer over charge exchange in acetonitrile and dichloromethane, whereas in hexanes there is little change in the relative amount of proton transfer (lower traces in Figures 1-6). Much of the apparent increase in proton transfer in acetonitrile or dichloromethane is due to a marked decrease in charge exchange; however, on an absolute basis carbon dioxide in all gas streams causes a significant increase in proton transfer. The source of the protons is puzzling since they cannot come from carbon dioxide and are unlikely to come from acetonitrile or dichloromethane. Because both solvents show the same effect, it may be reasonable to assume that the protons originate from impurities in the carbon dioxide. We have shown in the previous paper [6] that the predominant protonated species observed with only carbon dioxide present in the APCI source were protonated ethers and ketones. The PA values of these species are not much different from that of acetonitrile (for numbers see Table 1 in the previous paper [6]), or from protonated alkenes. Since a significant difference in PA values is required for proton transfer to occur efficiently [7], these impurities seem to be an unlikely source of protons capable of providing the increases observed. It may be possible that protonation of the PAHs could occur from some transient reactive species with too short a life to be observed in the gas-only experiments. It could also be that the apparent increase in protonation is due to competing ionization processes with different rate constants for each set of solvent/gas conditions.

Another important point to consider is the dramatic increase in charge exchange observed when carbon dioxide is introduced into the nebulizer gas stream, with nitrogen in the other two streams, for a total concentration of about $5 \%$ carbon dioxide in the source gases (acetonitrile or dichloromethane, upper traces in Figures 1-4). The admission of about $5 \%$ carbon dioxide into the source gases may quench some processes which inhibit efficient charge exchange of the analyte PAHs in the corona discharge. Others have noted interesting, but unexplained, effects of introducing varying amounts of carbon dioxide with nitrogen into a corona discharge [11]. For example, combinations of nitrogen and carbon dioxide could produce reactive species, which are not present when either gas is used alone, such as $\cdot \mathrm{NCO}$ [11]. It has also been suggested that carbon dioxide can be decomposed in a corona discharge into carbon monoxide and atomic oxygen [12]. It is also known that carbon dioxide is much more efficient at exchanging energy with electrons than is nitrogen [7, 13], although this may not be directly relevant to the processes occurring in an APCI source under positive-ion conditions. Another aspect to consider is whether there are effects from turbulent mixing, or lack thereof, of gases exiting from the nebulizer and sheath gas streams, or whether there are molecular mass or volume effects from using different gases. Finally, it should be noted that carbon dioxide $(\mathrm{B}+\mathrm{S}+\mathrm{N})$ with hexanes as solvent actually gave a larger increase in charge exchange than in proton transfer, as compared to experiments where there was some nitrogen in the gas streams, see Table 2 and Figures 5, 6.

Examination of the responses of individual compounds to the set of different solvents and gas streams was also instructive. In general, the signal intensities of the $\mathrm{M}^{+\cdot}$ ions increase with decreasing IE (Table 1) and the signal intensities of the $[\mathrm{M}+\mathrm{H}]^{+}$ions increase with increasing PA. Thus naphthalene (1) and triphenylene (7) which have both higher IE and lower PA values tend to produce lower total ion currents while perylene (8), pyrene (4) and chrysene (6) which have lower IE and higher PA values are consistently observed with higher sensitivities. However, the order of increasing ion currents is not the same in each solvent and there are some obvious anomalies, e.g., fluorene (2) exhibits a higher than expected propensity to undergo proton transfer in all solvents, but especially in acetonitrile, and the level of charge exchange for pyrene (4) is very low in acetonitrile. The responses of the compounds containing heteroatoms, 9-11, have been discussed in the previous paragraphs.

Protonation of the PACs in acetonitrile must largely occur from the major protonated species in this solvent, namely $\left[\mathrm{CH}_{3} \mathrm{CNH}\right]^{+}$, which is a modest Brønsted acid, whereas protonation in the case of hexanes must come from a range of carbocations. It appears that these are more efficient at proton transfer under the conditions in the Quattro APCI source. As was noted in the previous paper [6] dichloromethane is stabilized by hydrocarbons so it may be expected that protonation in this solvent is also effected to some degree by carbocations. The number of ion counts observed for the protonated molecules of the PAHs 1-7, when these were dissolved in hexanes and with using carbon dioxide $(\mathrm{B}+\mathrm{S}+\mathrm{N})$ (Table 2), formed a sequence which very closely mirrors the PA values (Table 1) of these seven hydrocarbons. The numbers also generally follow the relative rates for 
Table 3. Ratios of intensities for protonated molecules to molecular ions, with assignments, from the analysis of a light gas oil using two different gas flows

\begin{tabular}{|c|c|c|c|c|}
\hline$m / z$ & $\mathrm{PAH}$ & {$[\mathrm{M}+\mathrm{H}]^{+} / \mathrm{M}^{+\cdot a}$} & {$[\mathrm{M}+\mathrm{H}]^{+} / \mathrm{M}^{+\cdot b}$} & Enhancement $^{\mathrm{c}}$ \\
\hline $216 / 217$ & Methylpyrenes & 1.61 & 0.62 & 2.5 \\
\hline $220 / 221$ & Trimethylphenanthrenes & 0.35 & 0.19 & 3.0 \\
\hline $230 / 231$ & Dimethylpyrenes & 2.87 & 1.65 & 2.3 \\
\hline $232 / 233$ & Tetramethyldihydrophenanthrenes or dimethyldihydropyrenes & 1.45 & 0.36 & 2.4 \\
\hline $242 / 243$ & $\begin{array}{l}\text { Trimethyldihydropyrenes or methylchrysenes or } \\
\text { methylbenzanthracenes }\end{array}$ & 1.20 & 0.70 & 2.3 \\
\hline $256 / 257$ & $\begin{array}{l}\text { Tetramethyldihydropyrenes or dimethylchrysenes or } \\
\text { dimethylbenzanthracenes }\end{array}$ & 1.03 & 0.50 & 1.9 \\
\hline
\end{tabular}

${ }^{a} D-N i t r o g e n$ in all three gas streams.

${ }^{b} \mathrm{D}$-Nitrogen as bath and sheath gas, carbon dioxide as nebulizer gas.

'Ratio of $\mathrm{M}^{+\cdot}$ with $\mathrm{CO}_{2}$ as nebulizer gas to $\mathrm{M}^{+\cdot}$ with $\mathrm{N}_{2}$ as nebulizer gas.

protodetritiation reactions in trifluoroacetic acid, a technique used to evaluate the relative reactivity of PAHs to electrophilic aromatic substitution reactions [14-16]. Thus, the protonation processes observed in the APCI source appear to be the same as those for electrophilic aromatic substitution reactions in solutions, which also involve ring protonation.

\section{Practical Application: The Analysis of a Light Gas Oil}

An application of the studies described in this and the preceding paper to a practical problem was done by carrying out an HPLC separation with acetonitrile as solvent on a pyrene-containing fraction from a light gas oil sample, using APCI(+)MS for detection. This fraction was obtained by carrying out a classical, normalphase separation of the oil fraction on silica gel using hexanes as eluent. Traditionally, final analysis would have been carried out by gradient elution on a reversedphase HPLC column, beginning with a 50:50 (vol/vol) acetonitrile-water mixture, progressing to pure acetonitrile and, in certain circumstances, ending with addition of dichloromethane. It has been found that using a longer column immersed in an ice bath at $0{ }^{\circ} \mathrm{C}$ and running the reversed-phase HPLC isocratically using only acetonitrile as eluent provided the same degree of separation as with a gradient involving mixtures of water and acetonitrile [8, 17, 18]. This permitted much higher sensitivity to be obtained when using APCI(+)MS detection. The ions observed, as described in the Experimental section and listed in Table 3, include those from compounds with 10 to 13 double bond equivalents, e.g., alkylated phenanthrenes, pyrenes, and chrysenes.

The results in Figure 7 show the mass spectral total ion current (TIC) obtained by summing the responses in counts of the ions listed in Table 3 . The upper scan shows an analysis using D-nitrogen $(B+S+N)$, while in the lower scan D-nitrogen $(B+S)$ with carbon dioxide $(\mathrm{N})$ was used. Acquisitions were continued until peaks were no longer observed. The two scans are not precisely synchronized with respect to time. These data illustrate the increase in sensitivity that can be achieved by introducing carbon dioxide into the nebulizer gas stream; not shown is the increase in sensitivity achieved by excluding water from the chromatographic eluent. The protonation ratios are consistent with those for the reference PAHs, as given in Figures 1 and 2, again indicating that the increase in sensitivity on using carbon dioxide in the nebulizer stream is achieved by an increase in charge exchange.

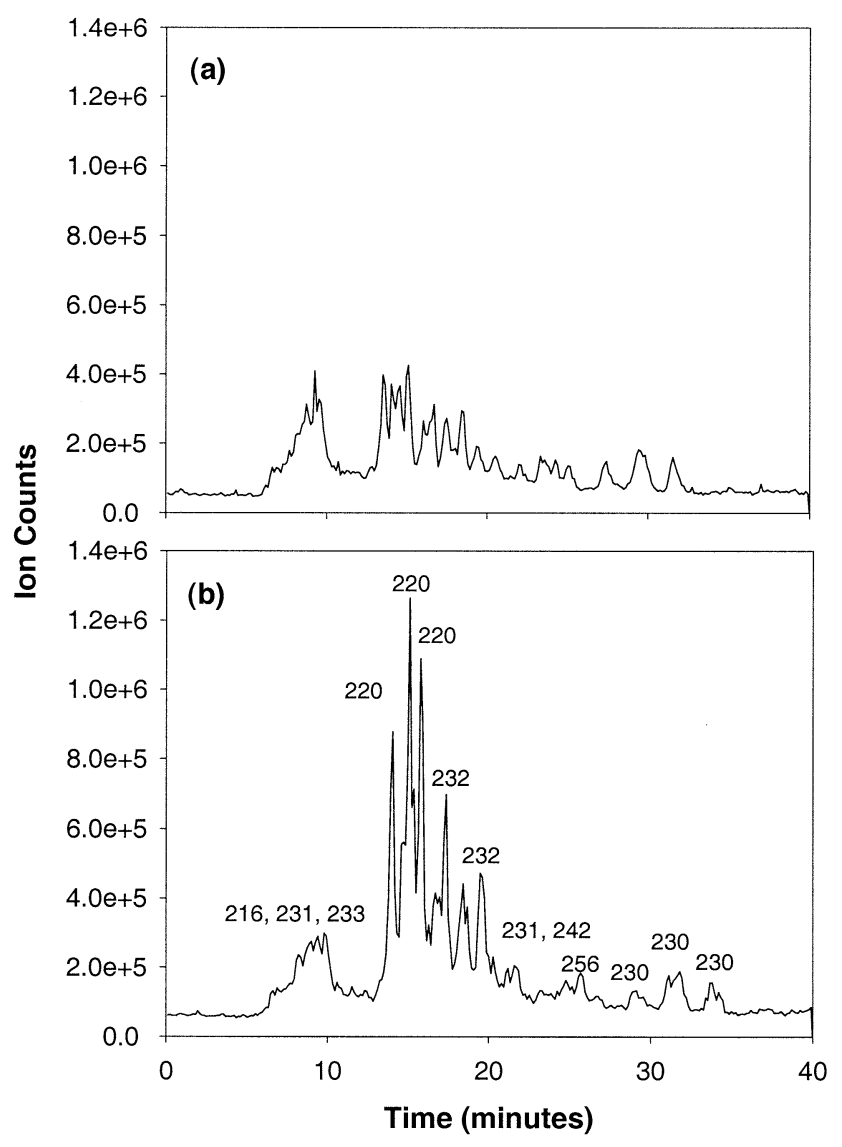

Figure 7. The total ion chromatograms observed for a fraction of a light gas oil containing pyrenes with (a) only D-nitrogen in the APCI gas streams, and (b) D-nitrogen in the bath and sheath gas streams with $\mathrm{CO}_{2}$ in the nebulizer stream (for full details see text). 


\section{Conclusions and Analytical Implications of This Work}

In terms of general trends for the compounds in this study, total response decreases in the order: Hexanes $>$ dichloromethane $>$ acetonitrile $\gg$ aqueous acetonitrile. Ionization by proton transfer increases (on an absolute basis) in the order: Acetonitrile $\leq$ aqueous acetonitrile $<$ dichloromethane $<$ hexanes; charge exchange is the preferred ionization mechanism in acetonitrile and aqueous acetonitrile; addition of carbon dioxide to the gas flows, except for the case of nitrogen $(B+S)$ and carbon dioxide $(\mathrm{N})$, increases the degree of proton transfer; addition of air (oxygen) to the gas flows increases the degree of charge exchange. If ionization of PACs was purely by interaction with source gas-derived ions, the nature of the solvent should have no effect or it would simply reflect changes in sampling efficiency with variations in solvent. The sampling efficiency then would be dependent on factors such as droplet size (solvent surface tension) and desolvation (solvent heat of vaporization and boiling point). The differences in response between solvents is not related to the solvent ion background or the abundance of the base peak in the solvent background. Likewise, if ionization was purely by interaction with solvent-derived ions, the nature of the source gases would have no effect or this would reflect changes in sampling efficiency with variations in gas flows. Sampling efficiency would then be dependent on factors such as gas thermal conductivity. Our data clearly indicate that both the sensitivity and the ionization mechanism are strongly dependent on both the solvent and source gases employed. Thus, in addition to direct ionization in the corona discharge, solvent and gas-derived ions must interact with each other in subtle ways to ionize analytes.

In many analytical procedures, and especially when using HPLC, the eluent is not chosen to provide maximum mass spectral sensitivity. In situations where acetonitrile or dichloromethane must be used, the use of air in all three gas streams or nitrogen $(B+S)$ with carbon dioxide $(\mathrm{N})$ will improve sensitivity. Of these two choices, the latter provides the more inert conditions. If at all possible, conditions should be adjusted to allow the use of acetonitrile without the addition of water. From an economic standpoint, the use of high quality carbon dioxide in any of the gas streams will increase the cost of analysis. The optimum gas mixture from the point of both cost and enhanced signal response was nitrogen $(B+S)$ and carbon dioxide $(N)$. In the case of certain infusion or flow-injection experiments, a wider range of solvents is available. The results of this study indicate that, for nonpolar molecules that can be ionized by either proton transfer or charge exchange, hexanes (or isooctane, as shown in the previous paper [6]) in combination with carbon dioxide in all three gas streams would provide the maximum sensitivity.

The improvements in sensitivity when using carbon dioxide in the nebulizer gas stream have important implications for supercritical fluid chromatography since carbon dioxide is by far the most common supercritical eluent and acetonitrile is a convenient modifier. In fact, we have shown that APCI is a good ionization method when a supercritical fluid chromatograph is coupled to the Quattro mass spectrometer, providing good sensitivity for the more nonpolar PAHs such as those used in this study [1].

The present studies indicate that the ionization behavior of nonpolar analytes in a liquid introductionatmospheric pressure chemical ionization source, such as that for the Micromass Quattro spectrometer, cannot be understood by invoking the classical reaction mechanisms involving proton transfer using hydronium ions, discussed in the previous paper [6]. The studies have shown that complex interactions take place between gas- and solvent-derived ions in the ionization process. The relative reactivity and abundance of these reagent ions is responsible for both the observed signal intensity and the predominant ionization mechanism of the analytes. The structures of the analytes are also important in the ionization process. The results have shown that it is possible to use APCI to ionize nonpolar molecules having relatively low ionization energies by electron transfer processes. This form of ionization can lead to useful analytical methods even if the proton affinities of the analytes are too low for effective proton transfers to occur in the APCI source. It must be emphasized that the results presented in this paper may be instrument-specific and may not apply to other instruments with a different source geometry and/or gas flow system.

\section{Acknowledgments}

The authors thank Imperial Oil Ltd, Syncrude Canada, and the Natural Sciences and Engineering Research Council of Canada for financial and technical support of this work. R. D. Guy and M. A. Potvin carried out the isolation of the pyrene-containing fractions of the light gas oil and engaged in helpful discussions. BMK thanks the Walter C. Sumner Foundation for a Memorial Fellowship and Dalhousie University for a Graduate Faculty Scholarship.

\section{References}

1. Ramaley, L.; Guy, R. D.; Mercier, G. Two-Dimensional Chromatography Using SFC and GC/MS to Investigate Refining Processes in the Preparation of Light Gas Oils and other Materials. Proceedings of the 51st ASMS Conference on Mass Spectrometry and Allied Topics; Montréal, P.Q., June, 2003; paper \# ThOFam 10:35.

2. Roussis, S. G.; Fedora, J. W. Quantitative Determination of Polar and Ionic Compounds by Atmospheric Pressure Chemical Ionization and Electrospray Ionization Mass Spectrometry. Rapid Commun. Mass Spectrom. 2002, 16, 1295-1303.

3. Hughey, C. A.; Hendrickson, C. L.; Rodgers, R. P.; Marshall, A. G.; Qian, K. N. Kendrick Mass Defect Spectrum: A Compact Visual Analysis for Ultrahigh-Resolution Broadband Mass Spectra. Anal. Chem. 2001, 73, 4676-4681.

4. Galceran, M. T.; Moyano, E. Determination of Hydroxy Polycyclic Aromatic Hydrocarbons by Liquid ChromatographyMass Spectrometry. Comparison of Atmospheric Pressure Chemical Ionization and Electrospray. J. Chromatogr. A 1996, 731, 75-84. 
5. Marvin, C. H.; Smith, R. W.; Bryant, D. W.; McGarry, B. E. Analysis of High-Molecular-Mass Polycyclic Aromatic Hydrocarbons in Environmental Samples Using Liquid Chromatography-Atmospheric Pressure Chemical Ionization Mass Spectrometry. J. Chromatogr. A 1999, 863, 13-24.

6. Kolakowski, B. M.; Grossert, J. S.; Ramaley, L. Studies on the Positive Ion Mass Spectra from Atmospheric Pressure Chemical Ionization of Gases and Solvents Used in the Analysis of Polycyclic Aromatic Compounds. J. Am. Soc. Mass Spectrom, 2003, in press.

7. Harrison, A. G. Chemical Ionization Mass Spectrometry, 2nd ed; CRC Press: Boca Raton, FL, 1992, pp 71-112.

8. Potvin, M. A. Multidimensional Chromatographic Methods for Polycyclic Aromatic Compounds in Complex Environmental Samples; Ph.D. Thesis, Dalhousie University, 2002, p 50.

9. Kolakowski, B. M. Studies on the Response to Polycyclic Aromatic Compounds of Liquid Introduction-Atmospheric Pressure Chemical Ionization Mass Spectrometr; Ph.D. Thesis, Dalhousie University, 1999, pp 71, 72.

10. Tung, Y. Y.; Field, F. H. Chemical Ionization Mass Spectrometry XIX: $n$-Hexane and $n$-Octane as Reagents. Org. Mass Spectrom. 1974, 8, 267-277.

11. Hensel, K.; Hayashi, N.; Yamabe, C.; Morvová, M. Positive DC Corona Discharge in $\mathrm{N}_{2}-\mathrm{NO}-\mathrm{CO}_{2}-\mathrm{O}_{2}$ Mixtures. Jpn. J. Appl. Phys. Part 1 2002, 41, 336-345.
12. Chang, J-S.; Lawless, P. A.; Yamamoto, T. Corona Discharge Processes. IEEE Trans. Plasma Sci. 1991, 19, 1152-1166.

13. Warman, J. M.; Sauer, M. C., Jr. Investigation of Electron Thermalization in Irradiated Gases Using Carbon Tetrachloride as an Electron Energy Probe. J. Chem. Phys. 1975, 62, 1971-1981.

14. Wang, D. Z.; Streitwieser, A., Jr. An ab Initio Study of Electrophilic Aromatic Substitution. Theor. Chem. Acc. 1999, 102, 78-86.

15. Archer, W. J.; Taylor, R.; Gore, P. H.; Kamounah, F. S. Electrophilic Aromatic Substitution, Part 27. Protodetritiation of Chrysene. J. Chem. Soc. Perkin Trans. 2 1980, 1828-1831.

16. Ansell, H. V.; Hirschler, M. M.; Taylor, R. Electrophilic Aromatic Substitution, Part 18. Protodetritiation of Anthracene, Coronene (Dibenzo[ghi, pqr]Perylene, and Triphenylene in Anhydrous Trifluoroacetic Acid. J. Chem. Soc. Perkin Trans 2. 1977, 1972-1999.

17. Kurganov, A.; Unger, K. K.; Eisenbeiß, F. Separation of Polycyclic Aromatic Hydrocarbons Under Isocratic Conditions by a Column Switching Technique. Chromatographia 1994, 39, 175-179.

18. Mäkelä, M.; Pyy, L. Effect of Temperature on Retention Time Reproducibility and on the Use of Programmable Fluorescence Detection of Fifteen Polycyclic Aromatic Hydrocarbons. J. Chromatogr. A 1995, 669, 49-57. 